www.parentchannel.tv has met its ambitious targets. Within months of its launch, this outward-facing model has syndicated its content far and wide. Other sites are able to embed parentchannel.tv films on their sites thus reaching a far greater audience - all free of charge. Social networks for parents already exist on other sites to which www.parentchannel.tv is syndicated. Examples of evidence of how this initiative has achieved lifestyles changes. Parents and children have said:

- 'Given me ideas how to integrate my newly declared vegetarian into the family meal system'.

- 'My child is only five and I have been watching films of how to cope with my child when she is older - it gives me hope!'
- 'Understanding WHY children do the things they... it does help me to have patience'.

- 'I have learnt quick ways to keep calm - counting backwards in sevens-works!'

- 'My son who was being bullied at school came home the other day and I started watching PCTV and the bullying video - he pretended not to watch with me but I could see he was - after that we talked together and now things are so much better - thanks PCT'.

- A Tomorrow's Child Editor said: 'My son is only a baby but as I have been editing these films I have been storing away great ideas for when he gets older'.

New communication tools are working. These new tools offer an important means of empowering children.

\title{
Pilot study: a novel multidisciplinary approach for young obese children
}

\author{
E Van Hoek ${ }^{1}$, EJM Feskens ${ }^{2}$, LI Bouwman ${ }^{2}$ and AJ Janse ${ }^{1}$ \\ ${ }^{1}$ Hospital Ziekenhuis Gelderse Vallei, Ede, The Netherlands: ${ }^{2}$ Wageningen University and Research centre (WUR), \\ Wageningen, The Netherlands
}

Introduction: Because of the severe consequences of childhood obesity, there is a need for an effective intervention in young children. Therefore we have developed AanTafel!, a novel evidence- and practice-based intervention program for young obese children. This intervention is multidisciplinary, has a total duration of one year, and is focused at the parents. A digital workbook is part of this intervention. This workbook is for parents only and contains film fragments, information and assignments (e.g. dietarian diary).

Method: We performed a pilot study to assess the feasibility of AanTafel!, with special attention for the digital approach. A group of parents of seven obese children started treatment at 1 March 2010. After the intensive part of treatment (3-4 months) participation of parents, use of digital multimedia approach and the opinion of parents and therapists were evaluated.

Results: The presented results are after the first part of treatment of 3-4 months. Participation of parents in the meetings was well and there are no drop-outs. Four out of seven children succeeded in stabilizing there weight or reach a weight loss (of maximal $1 \mathrm{~kg}$ ). In these children the BMI decreased with a mean of $0.96 \mathrm{~kg} / \mathrm{m}^{2}$ (BMI-SDS $-0.38 \mathrm{~kg}$ / $\mathrm{m}^{2}$ ). One out of seven children increased in weight, but decreased her BMI with $0 \cdot 16 \mathrm{~kg} / \mathrm{m}^{2}$ (BMI-SDS $-0 \cdot 15 \mathrm{~kg} / \mathrm{m}^{2}$ ). In two children the BMI increased with a slight decrease $\left(-0 \cdot 11 \mathrm{~kg} / \mathrm{m}^{2}\right)$ or slight increase $\left(0 \cdot 06 \mathrm{~kg} / \mathrm{m}^{2}\right)$ in BMI-SDS for age. In the children without enough weight stabilisation interfering factors were discussed, and new goals were set. They are motivated to make new changes in the lifestyle. The digital program was positively rated by all parents. They called the digital program understandable, fun and clarifying. The digital program was correctly used in six out of seven parents. Parents value the information received on paper as a positive supplement, because they can make notations during the meetings and can easily look back in the information. Three parents would like to spend more time during the meetings to discuss the diaries. The digital approach helps therapists to individualize treatment. The therapist rated positive that they can read the diaries and other assignments before the start of each meeting. The therapists wish to have the possibilities to react over the internet at assignments made by parents.

Conclusions: The intervention program AanTafel! appeared to be feasible. The digital multimedia approach can be used in most parents of these children, and it helps therapists to individualize treatment. After this pilot study we adjusted the intervention program slightly. Even more time will be spent during the meetings in discussing the diaries and setting individual goals. For therapist it will be possible to give a personal reaction at an assignment made by a parent over the Internet. We think that this adjustment will improve the results. Evaluation of this program on effectiveness is needed. 